Meltem

İzmir Akdeniz Akademisi Dergisi

No. 5, Yaz 2019, 93-97, DOI 10.32325/iaad.2019.7

\title{
İzmir'de Gıda Grupları ve Topluluk Destekli Tarım*
}

\section{Fatih Özden**}

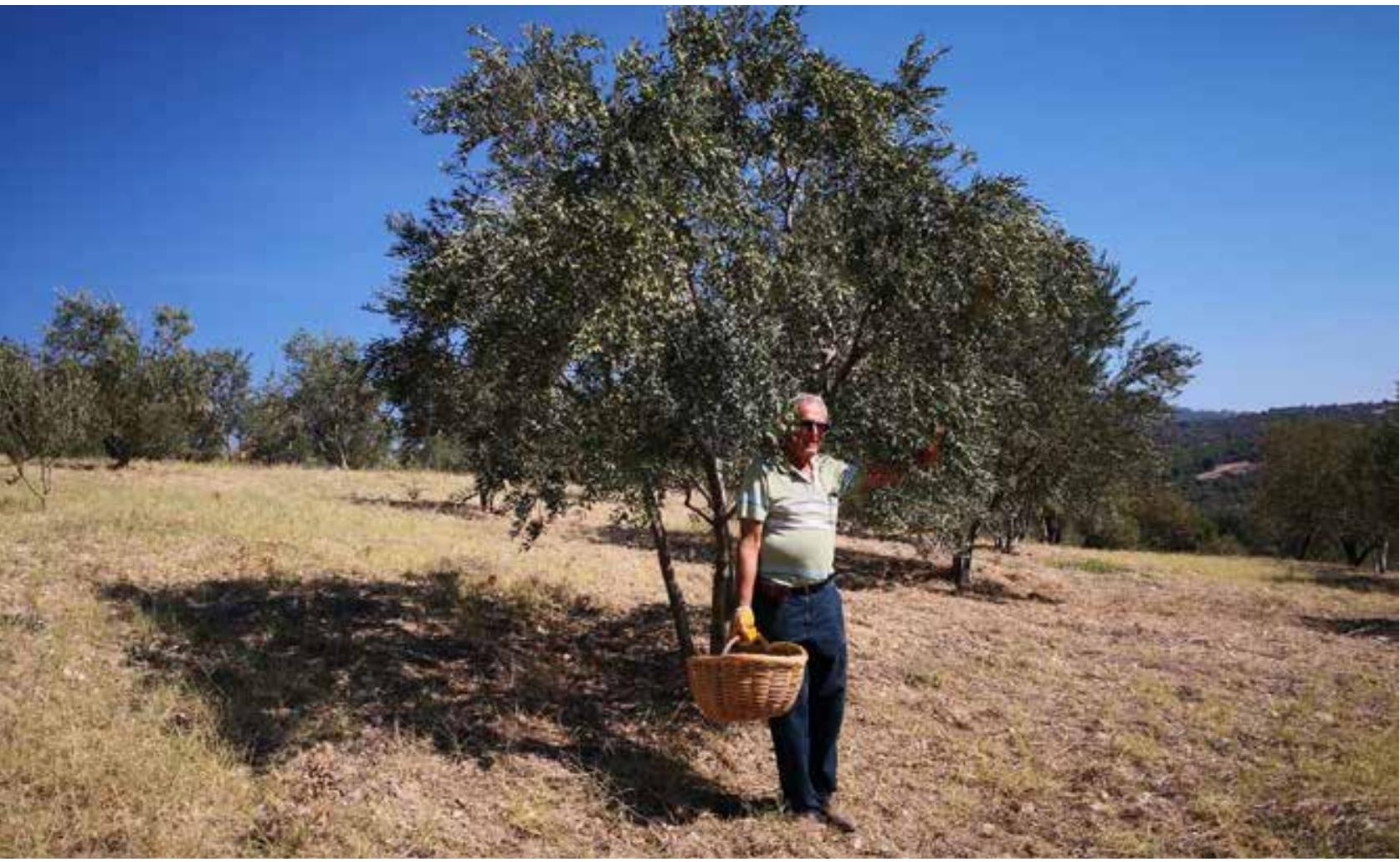

Yeşil devrim olarak adlandırılan ve 20. yüzyılın ikinci yarısında gündeme gelen tarımda hibrit tohum, suni kimyasal gübreler, tarım zehirleri ve aşırı fosil yakıt kullanımına dayanan endüstriyel tarım-gıda sistemi, bir yandan çiftçileri ve tüketicileri sosyal, ekonomik, kültürel açıdan olumsuz etkilerken diğer yandan doğada ve insan sağlığı üzerinde geri dönüşü zor tahribatlara neden oluyor. Kapitalist tarım-gıda sistemi çiftçileri ve tüketicileri doğaya, üretim süreçlerine, ürüne ve birbirlerine yabancılaştırmaktadır. Söz konusu bu yabancılaşmanın aşılabilmesi, yabancılaşmayı doğuran sistemin de aşılmasını gerektirmekle birlikte mevcut sistem içinde de çeşitli alternatifler gündeme gelmektedir. Son yıllarda dünyada ve Türkiye'de sayıları hızlıca artan ve kendi içlerinde de çeşitlilik gösteren gıda grupları bu alternatifler arasında yer alıyor.

Türkiye'de gıda grupları 2009'da kurulan Boğaziçi Üniversitesi Mensupları Tüketim Kooperatifi (BÜKOOP) ile gündeme gelmiştir. Süreç içerisinde İstanbul'da Direnen Üretici Tüketici Kooperatifi (DÜRTÜK), Yeryüzü Derneği Gıda Toplulukları, Kadıköy Tüketim Kooperatifi, Beşiktaş Kooperatif Girişimi, Şişli Kooperatif Girişimi, Koşuyolu Kooperatif Girişimi, Üsküdar Tüketim Kooperatifi Girişimi gibi gıda grupları oluşturulmuştur. Ankara'da ise 100. Yıl Gıda Topluluğu, Güneş-

* Fotoğraflar sırasıyla Gediz Ekoloji Topluluğu ve Batı İzmir Topluluk Destekli Tarım Grubu arşivi ile 5 Mayıs 2019'da gerçekleştirilen “izmir Gıda Toplulukları Panayırı”ndan.

** Ege Üniversitesi, Tarım Ekonomisi Bölümü 


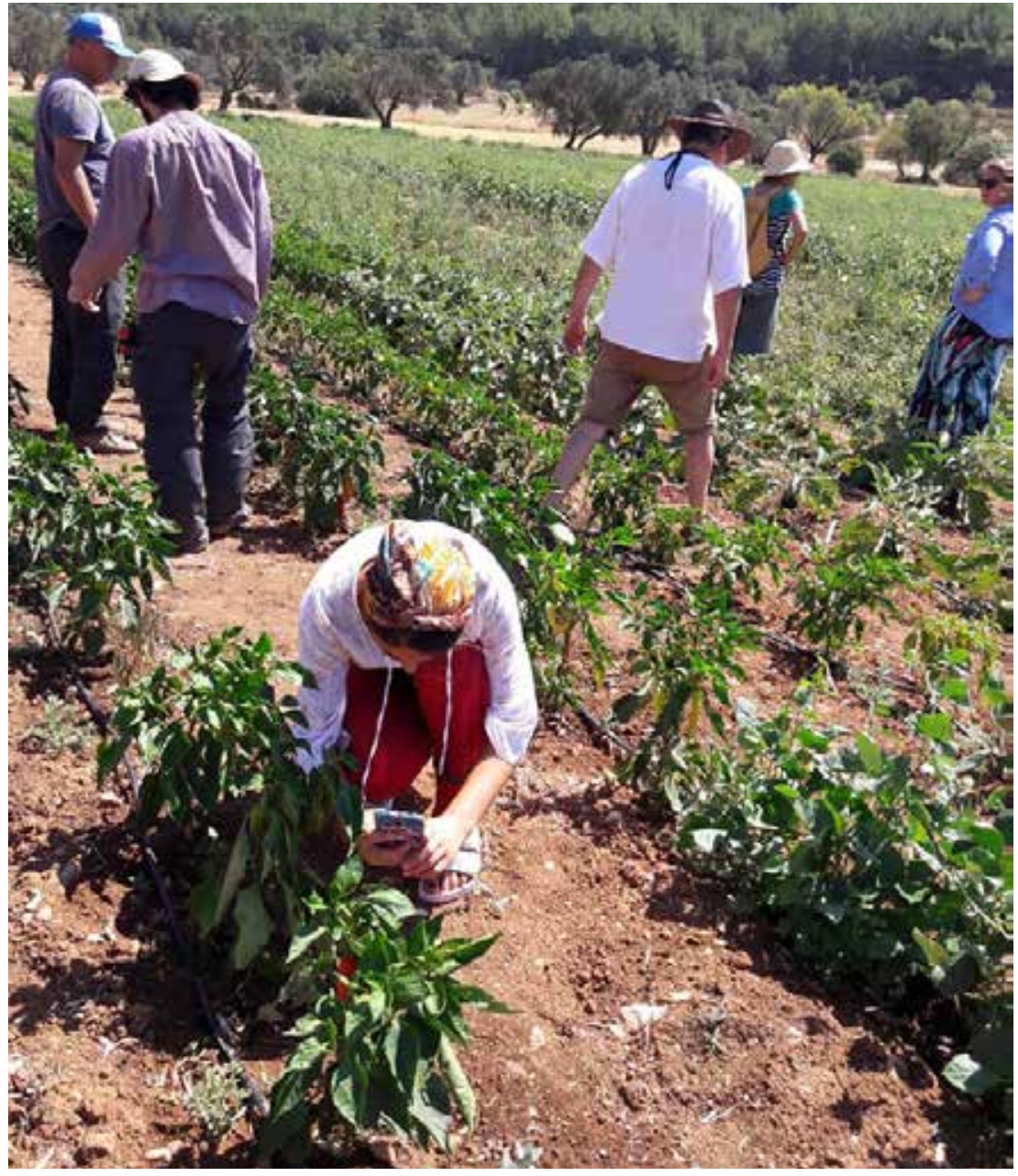

köy Kooperatifi gibi toplulukların yanında, doğa dostu yöntemlerle üretilen temiz, sağlıkı, güvenilir ürünlere aracısız ulaşabilmeyi kolaylaştırmak için Katılımcı Onay Sistemi üzerine çalışmalarını yürüten Doğal Besin, Bilinçli Beslenme Ağı (DBB) gibi gruplar kurulmuştur. Ayrıca Balıkesir'de Yaşam Dostu Ürün Dayanışma Üretim ve Paylaşım Grubu, Antalya'da Antalya Gıda Grubu, Muğla'da Bizim Bostan Topluluk Destekli Tarım Grubu ve Bodrum Tohum Derneği ile Gaziantep'te Yeşil Ev Tüketim Kooperatifi Girişimi sayılabilecek örnekler arasındadır.

İzmir'de gıda gruplarının başlangıcı ise 2012'de Ege Üniversitesi Ziraat Fakültesi Tarım Ekonomisi Bölümü'nde işyeri esaslı olarak kurulan Doğa ve İnsan Dostu Gıda Grubu'dur. Grubun kurulmasında önemli katkıları olan Prof. Dr. Tayfun Özkaya'nın girişimleriyle üniversite içinde İktisat Bölümü'nde, Halk Sağlığı ve Patoloji Anabilim Dallarında olmak üzere üç grup daha oluşturulmuştur. Daha sonraki dönemde İzmir'de kurulan diğer gıda grupları ise Urla merkezli Batı İzmir Topluluk Destekli Tarım Grubu (BITOT), Karşıyaka merkezli Gediz Ekoloji Topluluğu (GeTo) ve Bornova merkezli kurulan Homeros Gıda Topluluğu'dur.

Son zamanlarda İmir'deki gıda toplulukları arasındaki iletişimi güçlendirmek ve işbirliği olanaklarını geliştirmek amacıyla çeşitli buluşmalar gerçekleştirilmektedir. Bu buluşmalardan ilki Ekim 2018'de yapıldı. İlk toplantı sonrasında üretici çalışma grubu ile tüketici ve tanıtım çalışma grubu olmak üzere topluluklardan temsilcilerin bulunduğu gruplar oluşturuldu. Çalışma gruplarının 


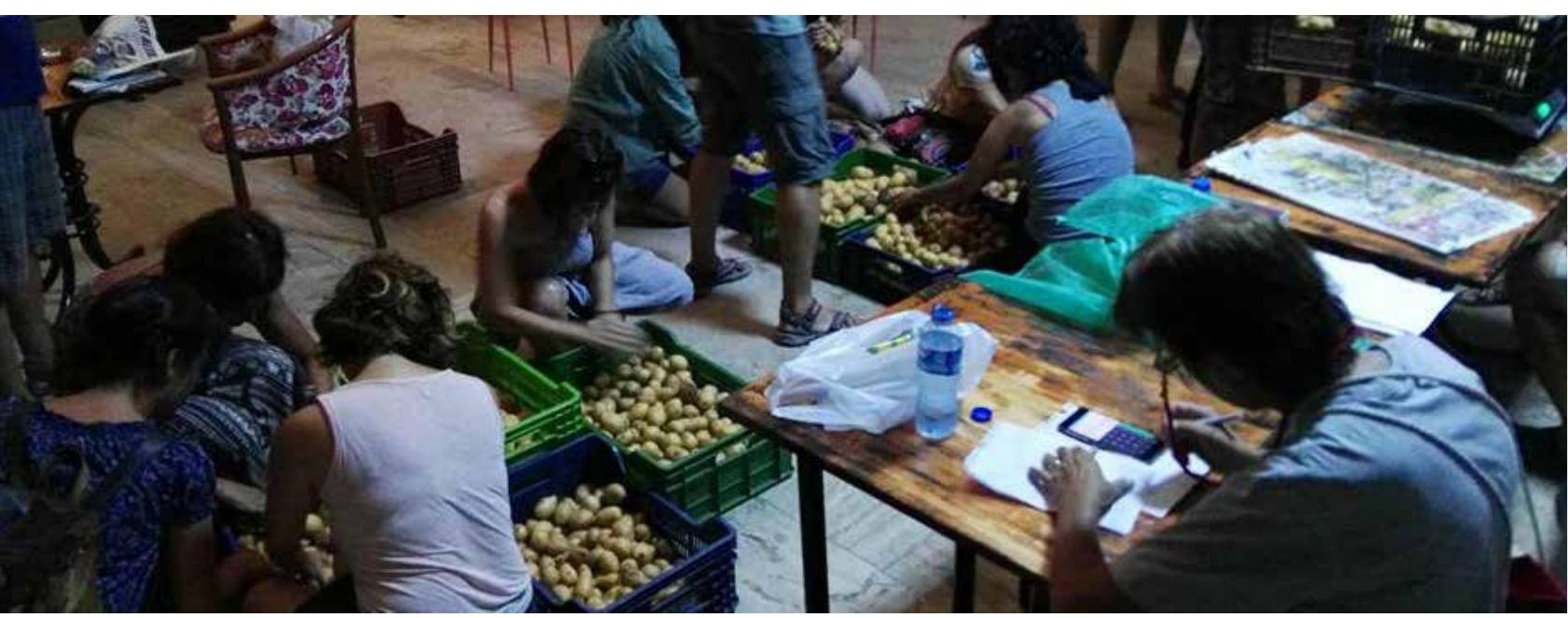

yapmış oldukları toplantılarda da gıda gruplarının senenin belirli dönemlerinde birlikte etkinlik düzenlemeleri yönünde bir irade oluştu. Bu iradenin bir yansıması olarak 5 Mayıs 2019 günü “izmir Gıda Toplulukları Panayııı" başlığılla herkese açık bir buluşma gerçekleştirildi. Bu buluşmada ilk olarak çeşitli sunumlar yapııdı. Sunumların ardından buluşmaya katılanlar gıda grupları için doğa dostu yöntemlerle üretim yapan üreticilerle tanışma ve ürünlerinden alma fırsatı buldular.

Buluşmanın sunumlardan oluşan ilk bölümünün açılışını yapan GeTo'dan Oya Ayman, genel olarak gıda topluluklarından ve gıda gruplarının hedeflerinden bahsetti. Açılış konuşmasının ardından BITOT'dan Tamer Güvenir İzmir'deki gıda gruplarını tanıtan bir sunum gerçekleştirdi ve Ege Üniversitesi, BITOT, GeTo ve Homeros gruplarının hikâyesini ve işleyişlerini aktardı. Etkinliğe İzmir dışından Kars Boğatepe Çevre ve Yaşam Derneği adına katılan İlhan Koçulu ise sunumunda yörede gerçekleşen sosyo-ekonomik kalkınma sürecinden ve bu süreçte yöre ürünlerinin pazarlanmasında gıda topluluklarının nasıl bir rolü olduğundan bahsetti.

Buluşmada ben de bir sunum yaptım. Sunumumun başıı̆ını, Kasım 2018'de Selanik'te katıldığım Uluslararası Topluluk Destekli Tarım Ağı (The International Network for Community Supported Agriculture - URGENCI) tarafından düzenlenen sempozyumun çağrı metninin de başlığı olan "Sınırların Ötesinde Topluluk Destekli Tarım" olarak belirledim. ' Sunumumda ilk olarak her gıda grubu aynı zamanda bir Topluluk Destekli Tarım (TDT) grubu mudur sorusuna yanıt vermeye çalıştım. Ardından TDT'nin geçmişinden, çeşitli TDT modellerinden ve dünya örneklerinden bahsettim. Ayrıca sunuma başlığını veren Selanik'teki sempozyuma ilişkin izlenimlerimi paylaştım. Aşağıda kısaca bu sunumda üzerinde durduğum konuları aktarmaya çalışacağım.

Her gıda grubu bir TDT grubu değildir. Zira gıda grupları sadece sağlıklı ve güvenilir gıdaya doğrudan, aracısız olarak ulaşmak için gıda tedarikini öncelerken, TDT grupları üreticilerle sosyal ve ekonomik boyutları olan çok daha kapsamlı bir ilişki içine girmektedirler. Bu ilişkinin özünü risklerin, sorumlulukların ve ödüllerin paylaşıması oluşturmaktadır. Üreticilerle böylesi bir ilişki içinde olan ve gıdasına sahip çıkarak, çiftçinin sorunlarının farkında olan, bu sorunların çözümüne katkı sunmaya çalışan alıcılar tüketici olarak değil türetici olarak tanımlanmaktadır. İzmir'dekiler de dahil olmak üzere, bugün için Türkiye'deki birçok gıda inisiyatifinin TDT'yi kendilerine ulaşılacak bir hedef olarak belirlediklerini söyleyebiliriz.

TDT'nin kökleri 1971'de Japonya'da hem filozof hem de kooperatif lideri olarak tanınan Teruo Ichiraku'nun tarımda kimyasal kullanımının tehlikeleri konusunda bir kamuoyu oluşturarak agro-ekolojik bir tarım hareketini başlatmasına ve bir grup kadının Teikei (işbirliği) Projesi'ni başlatmak

1 URGENCI, "CSA Beyond Borders Conference Launched in Thessaloniki", Basın Bildirisi, Selanik, 9 Kasım 2018, https://urgenci.net/csa-beyond-borders-launched-in-thessaloniki/, erişim tarihi 1 Temmuz 2019. 
için çiftçilerle bir araya gelmesine kadar uzanır. Ichiraku organik tarımı sadece kimyasal kullanılmadan yapılan bir üretim biçimi olarak görmenin, karşı karşıya olunan birçok paradoksal ve sistemik sorunun gözden kaçııımasına neden olacağını ifade etmektedir. Sorunun çözümünün ise agro-ekolojik/doğa dostu bir üretimden, üreticilerle tüketicilerin işbirliğinden, seçim ve paketleme işlemlerinin basitleştirilmesinden, tüketim alışkanlıklarının değiştirilmesinden ve fiyatların katılımcı bir şekilde belirlenmesinden geçtiğini belirtmektedir. ${ }^{2}$ Japonya'nın ardından İsviçre, ABD, Almanya, Hindistan gibi dünyanın farklı birçok bölgesinde benzeri gruplar kurulmaya başlamış; günümüzde bu gruplar çok daha yaygın hale gelmiştir.

TDT, üreticilerle tüketiciler arasında risklerin, sorumlulukların ve ödüllerin paylaşıldığı sosyo-ekonomik ve kültürel bir ilişki biçimi olarak tanımlanır. Bu ilişkinin kurulması birbirinden farkı birçok yolla olabilmekte ve ortaya birbirinden farklı birçok model çıkabilmektedir. Katılımcı çiftlik sayısına, üyelerin katılımına ve verdikleri ekonomik güvencenin derecesine göre veya grupça kimin organize edildiğine bağlı olarak değişen TDT modellerinden bahsedilebilir.

Katılımcı çiftlik sayısına göre topluluklar, tek çiftlikli ve iki ya da daha fazla çiftlikli TDT grupları olarak ayrılabilmektedir. Bazı örneklerde çiftliğin yönetimi kolektif olarak gruba ait olabilmekte, grup üyeleri gıda intiyaçlarının büyük bir bölümünü bu çiftlikten karşılayabilmektedir. İki veya daha fazla çiftlikli modellerdeyse her bir çiftçi ve tüketici, aralarındaki sözlü veya yazılı anlaşma çerçevesinde üretim yapmaktadır.

TDT grupları tek bir çiftçinin veya iki ya da daha fazla çiftçinin bir araya gelmesiyle ve tüketicilere ulaşmasıyla oluşturulabildiği gibi türeticilerin çiftçilerle temas kurmasına da dayalı olabilmektedir. Ayrıca çiftçi-türetici güdümünde ortaklaşa ilerleyen TDT grupları da bulunmaktadır.

TDT gruplarında üretici ve türeticilerin katıımına göre farklı modeller ortaya çıkabilmektedir. Türeticilerin çiftlik işlerinde gönüllü çalışmasına, ürün dağıımına katılmasına, sosyal etkinlikler için çiftlik arazisinin türeticilere açılmasına, çiftçilerin belirli bir alanı üretim yapabilmeleri için türeticilere kiralayarak onlara bilgi desteği vermesine, yılın belirli dönemlerinde çiftçinin tatil yapabilmesi için veya bir hastalık durumunda türeticilerin çiftlik işlerinde sorumluluk almasına bağı olarak farklı örnekler ve modeller gündeme gelebilmektedir. Ayrıca türeticiler tarafından verilen ekonomik güvencenin derecesine göre de gruplarda farklılaşmalar olabilmektedir. Örneğin, üretim dönemi öncesi çiftçiye finansman sağlamak amacıyla ödeme yapılıp yapılmaması, kötü hasat riskine türeticiler tarafından ortak olunup olunmaması ve fiyatların belirlenmesinde gelir düzeyinin dikkate alınıp alınmaması bu farkılış̧manın ortaya çıkmasında etkili olabilmektedir. ${ }^{3}$
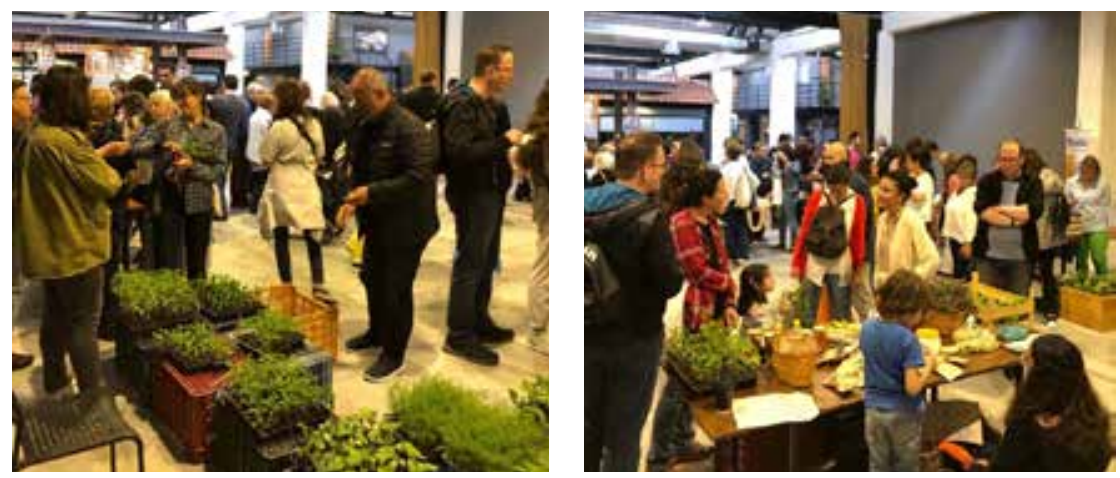

2 Japan Organic Agriculture Association, “'TEIKEI' system, the producer-consumer co-partnership and the Movement of the Japan Organic Agriculture Association", Country Report for the First IFOAM Asian Conference, 19-22 August 1993, Hanno, Saitama, Japan, http://www.joaa.net/english/teikei.htm, erişim tarihi 1 Temmuz 2019.

3 Jade Bashford, Kathleen Cross, Wolfgang Eichinger, vd., European Handbook on Community Supported Agriculture: Sharing Experiences (Viyana: Community Supported Agriculture for Europe Project, 2013), https://urgenci.net/wp-content/uploads/2015/03/CSA4EUrope_Handbook.pdf, erişim tarihi 1 Temmuz 2019. 


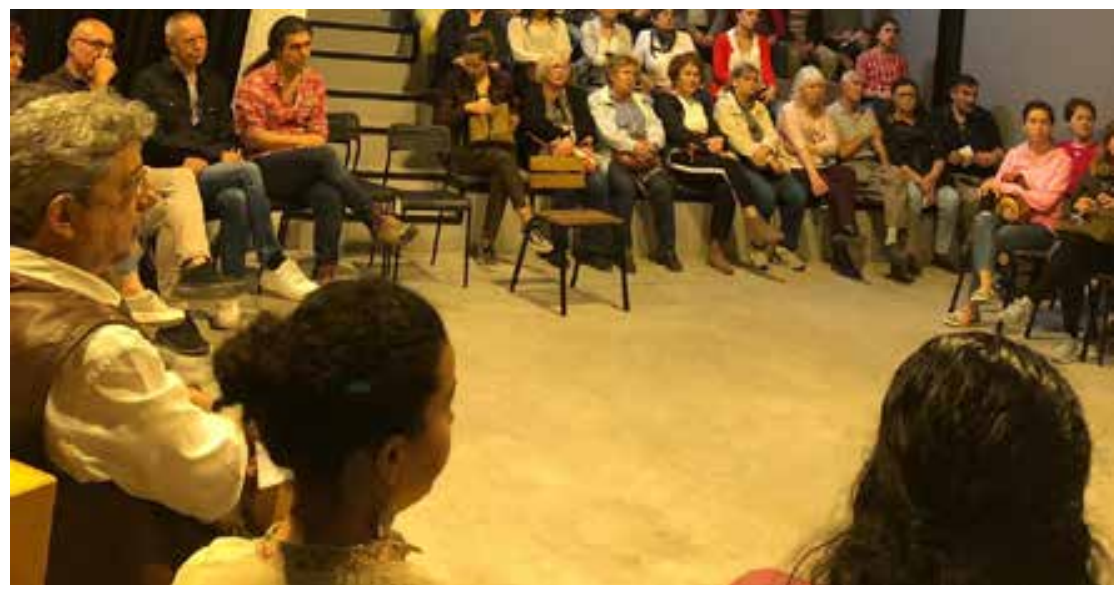

Bahsi geçen farklı TDT gruplarından birçoğu dünya ölçeğinde URGENCI çatısı altında sağlıklı gıdaya aracısız erişim, agro-ekolojik sistemlerin desteklenmesi, gıda egemenliği ve gıda adaleti gibi konularda ortak mücadele ve dayanışma olanağı bulmaktadırlar. Yaklaşık iki milyon kişinin temsil edildiği ağa tekil TDT grupları ile ulusal ve bölgesel TDT ağları, kooperatifler, üreticiler, türeticiler, araştırmacılar ve gönüllüler dahil olabilmektedir. UGRENCI tarafından düzenlenen sempozyum, kongre ve çalıştay benzeri etkinliklerde TDT ilgilileri bir araya gelerek bilgi ve deneyim paylaşımında bulunmaktadır. Bu etkinliklerden sonuncusu "Sınırları Ötesinde Topluluk Destekli Tarım” başlığıyla Kasım 2018'de Selanik'te gerçekleştirilmiştir. Dünyanın dört bir yanından 40 farklı ülkeden yaklaşık 300 kişinin katıldığı buluşmada TDT ve gıda egemenliği başta olmak üzere agro-ekoloji, dayanışma ekonomisi, müşterekler, katılımcı onay sistemi gibi farklı konular üzerinde durulmuştur.

Gıda toplulukları ve TDT konusu her geçen gün daha fazla ilgi görüyor. İzmir'de, gıda toplulukları buluşmaları dışında, 15-18 Mayıs 2019 tarihleri arasındaki İzmir Ekoloji Fuarı etkinlikleri çerçevesinde düzenlenen, yaklaşık 200 kişinin katıldığı "Gıda Toplulukları Paneli" fuarın en ilgi çeken oturumlarından birisi olmuştur. Aynı şekilde 29 Haziran 2019'da Dünya Tasarım Örgütü, Endüstriyel Tasarımcılar Meslek Kuruluşu, İzmir Akdeniz Akademisi ve İzmir Büyükşehir Belediyesi işbirliğiyle düzenlenen ve yine gıda topluluklarının temsilcilerinin katılımılla gerçekleştirilen "Tarladan Sofraya Gıdanın Sürdürülebilir Yolculuğunu Tasarlamak" başlıklı etkinlik de konunun ne kadar geniş kesimlerin dikkatini çektiğini göstermesi açısından anlamlıdır.

Evrensel İnsan Hakları Bildirgesi'nde de yer alan gıda hakkı, aynı yaşam hakkı gibi temel bir hak ve doğrudan halk sağlığını ilgilendiren bir konudur. Bugüne kadar toplumda bu sorunla ilgili hassasiyetler de göz önünde bulundurularak, mevcut tarım-gıda sistemine içkin ve sistemin açıkIarını kapamaya yönelik gıda güvenliği ve gıda güvencesi gibi kavramlar gündeme getirilmiştir. Ancak uzun zamandır gündemde olan bu kavramlar ne yazık ki gıdaya dair endişeleri gidermeye yetmemiş̧ir. Gıda egemenliği kavramı ise mevcut tarım-gıda sisteminin açıklarını kapamak yerine bu sorunların sisteme içkin ve onun doğal bir uzantısı olduğu kabulünden hareketle, farklı bir tarım-gıda sistemi için ekolojik, ekonomik ve politik içeriğe sahip kurucu bir kavram olarak karşımıza çıkmaktadır. Buradaki egemenlik doğrudan küçük çiftçilerin ve tüketicilerin egemenliğini ifade etmektedir. Tüketicilerin gıda üzerindeki egemenliği ise mevcut tarım-gıda sistemine tabi olmaktan çıkarak doğrudan sürece müdahil olabilmeleri ile mümkün olabilmektedir. Gıda toplulukları ve TDT grupları bu imkânın yaratı masının başlıca yollarından biridir. 